\title{
A procedure to evaluate the effect of lag-time in studying length structure and growth rate of young fish: the case of Phycis blennoides Brunnich, 1768 (Osteichthyes: Gadiformes) in the Central Mediterranean*
}

\author{
SERGIO RAGONESE ${ }^{1}$, FABIO FIORENTINO ${ }^{1}$, PAOLA RINELLI ${ }^{2}$ and \\ SILVESTRO GRECO ${ }^{2}$ \\ ${ }^{1}$ Istituto di Ricerche sulle Risorse Marine a l'Ambiente (CNR), Via Luigi Vaccara 61, \\ 91026 Mazara del Vallo (TP), Italy. \\ ${ }^{2}$ Istituto Sperimentale Talassografico (CNR), Spianata S. Raineri 86, 98122 Messina, Italy.
}

\begin{abstract}
SUMMARY: The joint analysis of data from different programs represents a good opportunity to improve knowledge about the condition of any exploited populations. This note investigates the influence of lag-time in sample characteristics (growth rate and recruitment) by following a simple and quick exploratory procedure. In order to illustrate this approach, the Greater Fork-beard (Phycis blennoides Brunnich, 1768), a species with discrete recruitment pattern and available to the capture process in the first years of life, was considered . The length-frequency distributions (LFD), obtained during five spring (MEDITS - International) and successive autumn (GRUND - Italian) bottom trawl surveys, conducted from 1994 to 1998, in the Strait of Sicily and Southern Tyrrhenian Sea (Mediterranean) were analysed. The procedure was divided into three steps. Firstly, the LFD were analysed in order to estimate the mean length of the first component in each survey. Secondly, for each survey, the difference between the standardized mean lengths of the first components in the LFD of the two areas was compared with the corresponding lag-time in order to assess any systematic temporal effect in recruitment periodicity. Thirdly, for each area, the absolute and instantaneous growth rates between the spring and autumn surveys of the same year were computed on the base of the lag-time, to evaluate any difference in growth rate between the areas. The results show that the earlier the surveys begin in the Strait of Sicily, the smaller is the difference in mean length. Since the growth rates between the two areas are practically indistinguishable, the higher mean lengths observed in samples from the Strait of Sicily mainly reflect the lag-time. The reference mean growth rate found (1.03 and $0.93 \mathrm{~cm}$ per month in the Strait of Sicily and Southern Tyrrhenian Sea, respectively) agreed with the literature. In spring, the recruits of 0 group represent up to $90 \%$ of the whole trawl catch, and the smallest length class observed (4.5$5.0 \mathrm{~cm}$ ) is close to the size of transition from the pelagic to the demersal one. The proposed exploratory procedure shows that systematic differences between the two investigated sub-areas in mean size and growth rate suggested by actual data are strongly reduced after having included the lag-time in the analysis.
\end{abstract}

Key words: trawl surveys, lag-time, growth rates, Phycis blennoides, Mediterranean.

\footnotetext{
*Received October 18, 2000. Accepted September 3, 2001.
} 


\section{INTRODUCTION}

Within the framework of limited budgets for fisheries research, joint analysis of data from different experiences represents a good opportunity to improve our knowledge of the condition of exploited populations (Hilborn and Walters, 1992). This exigency is of general application; for instance, tuning mortality estimates derived from indirect methods (VPA or LCA) with independent data extracted from trawl surveys is now a strongly recommended procedure (Pennington and Stromme, 1998).

Concerning Italian seas, two sources of data related to groundfish resources are available: one gathered within an Italian program (GRUND: Relini, 2000), the other within an international program (MEDITS: Bertrand et al., 2000). Both programs performed one trawl survey in each year with the same sampling scheme (stratification by depth and random allocation of the hauls among strata), but in different seasons (autumn and spring, respectively). The subunits involved in the trawl surveys employed the same sampling gear in successive times (MEDITS) and different sampling gear in the same period (GRUND), respectively (Fiorentini et al., 1998, 1999).

In order to improve knowledge about the status of a population, the integration of the data collected in adjacent subunits could be useful. However, in addition to problems of relative efficiency in the catching process, integrating samples should be preceded by an analysis of the differences in sampling periodicity, which might affect the results. Given that the bulk of the samples are represented by fast growing juveniles, ignoring "a priori" these effects can lead to an erroneous similarity/dissimilarity impression about the populations. Consequently, misleading assessment procedures might be implemented.

The main scope of this note is to investigate the influence of the lag-time in sample characteristics by following a simple and quick exploratory approach. A large-size species with a discrete recruitment pattern and susceptible to the capture process (at least in the first years of life), the Greater Fork-beard (Phycis blennoides Brunnich, 1768), was utilised for exemplary purposes. This species, of commercial value, occurs diffusely on the shelf edge and on the upper slope bottom in the areas covered by the two subunits (Fig. 1): the Southern Tyrrhenian Sea (STS) and the Strait of Sicily (SOS).

\section{MATERIAL AND METHODS}

A synthesis of the GRUND programs for each specific subunit can be found in Levi et al. (1998) and Greco et al. (1998). The trawler used by both subunits during the MEDITS program ("Sant'Anna") is the same employed by the SOS in the GRUND surveys. The technical characteristics of the "Sant'Anna" trawler are reported in Levi et al. (1998).

The characteristics of the two types of bottom trawl, the "ad hoc" developed GOC 73 (MEDITS) and the typical Italian commercial "tartana"

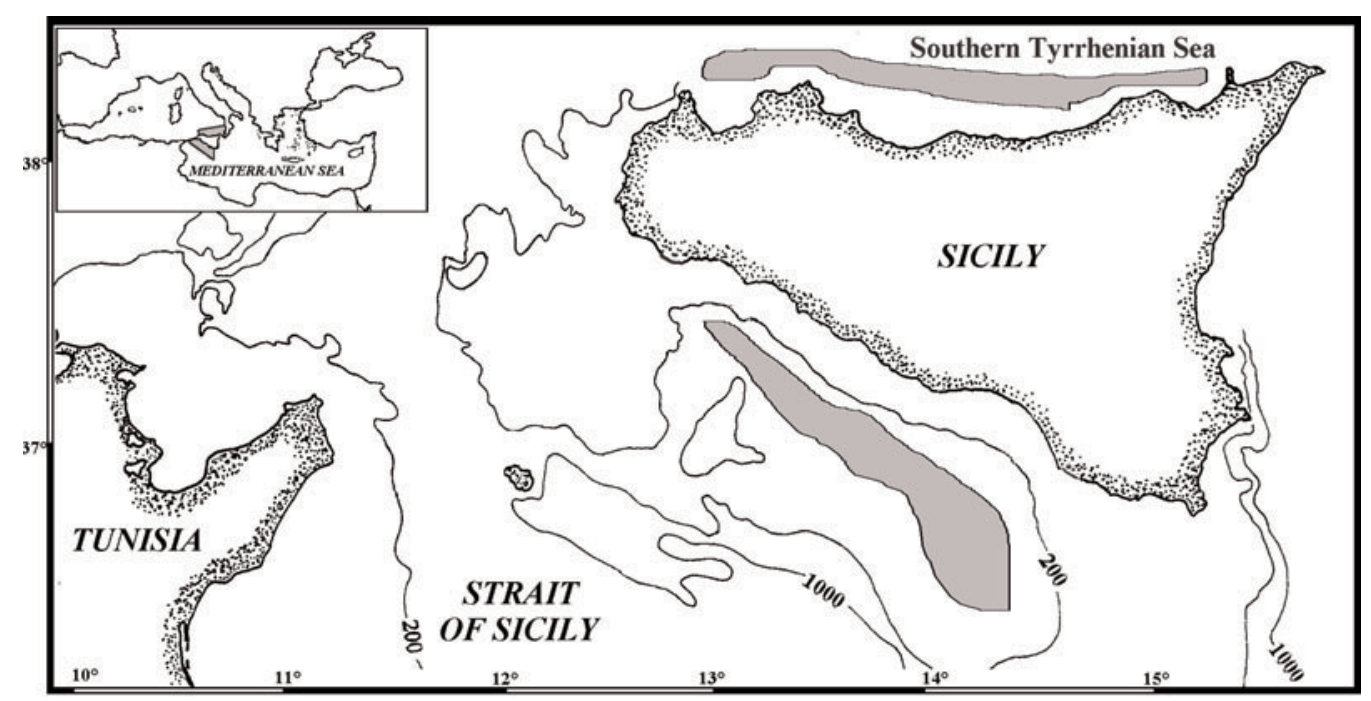

FIG. 1. - Study areas, characterized by the occurrence of the Great Fork-beard (Phycis blennoides) in the Central Mediterranean Sea: the Strait of Sicily (SOS) and the Southern Tyrrhenian Sea (STS), according to the MEDITS and GRUND surveys. 
(GRUND), as well as the efficiency of the two gears, are reported in Fiorentini et al. (1998, 1999). The steps of the procedure were as follows:

$1^{\text {st }}$ step: The length (total length) frequency distributions (LFD) of Phycis blennoides samples obtained in five spring (MEDITS) and successive autumn (GRUND) surveys, carried out from 1994 to 1998, by the SOS and STS, were analysed in order to estimate the mean length of the first component in each survey.

$2^{\text {nd }}$ step: For each season, the difference between the mean lengths of the first components in the LFD of the two subunits was computed. Given the increase in size between the MEDITS and GRUND surveys, these absolute differences were standardized according to the overall mean difference in each season and compared with the corresponding lagtime (differentials were computed always as SOS STS, taking the first day of the sampling periods as baseline) in order to assess any systematic temporal effect in recruitment periodicity, i.e.:

$$
\Delta \bar{l}_{i, j} \propto \Delta t_{i, j}
$$

where $i$ and $j$ denote the year and the survey, respectively.

$3^{\text {rd }}$ step: Within each subunit, the absolute $(\mathrm{g}=\Delta l / \Delta t)$ and instantaneous (specific) growth rates $(\mathrm{G})$ between the spring and autumn surveys of the same year, were computed on the base of the lagtime (in days). $G$ values were estimated according to the equation:

$$
\mathrm{G}_{i, k}=\frac{\log _{\mathrm{e}} \bar{l}_{2}-\log _{\mathrm{e}} \bar{l}_{1}}{t_{2}-t_{1}}
$$

where $i$ and $k$ denote the year and the subunit, respectively (Ricker, 1979).

After standardization to 1 month the $\mathrm{G}_{i, k}$ were used in order to evaluate any difference in growth rate between the subunits and to estimate a reference growth rate useful in assessing procedures.

The decomposition of the LFD was performed by using the maximum likelihood procedure NORMSEP, as implemented in the FiSAT package (Gayanilo et al.,1996). The required seed values were preliminarily obtained by the Bhattacharya procedure, always in FiSAT. The significance of the difference of the first component mean length were analysed by the classical t-test (one-tailed), taking into account the different sizes of the samples.

The relationship between the growth parameters and the time lag was evaluated by simple linear or non linear (parabolic) function fitted by least square regression.

The overall absence of significant differences between growth rates of the two investigated areas was tested by using the Wilcoxon signed ranks test.

The significance level of the statistical hypothesis (equality of the means, nullity of the correlation coefficient in the regressions and between areas variation in growth rates) was chosen at 5\% $(\mathrm{p}=0.05)$. In order to allow any comparison, the $\mathrm{p}$ value corresponding to each test was also reported. All the statistical analysis and tests were performed by using the SYSTAT program (SYSTAT, 1998).

Given the goal of the procedure (comparison of juveniles), males and females were considered together.

\section{RESULTS}

The MEDITS and GRUND sampling schedules, referring to years 1994-1998, are presented in Table 1 . The SOS unit carried out the MEDITS surveys systematically two weeks earlier than the STS unit (with the exception of the last year, 1998), resulting in an average delay of -11 days. On the contrary, no special

TABLE 1. - Lag-time in days among the trawl surveys (MEDITS and GRUND) for each subunit (Strait of Sicily, SOS and Southern Tyrrhenian Sea, STS) and between different subunits (expressed as differences in initial day SOS-STS). The overall $\Delta \mathrm{t}$ is referred to the difference

\begin{tabular}{|c|c|c|c|c|c|c|c|c|c|}
\hline Year & $\begin{array}{l}\text { SOS } \\
\text { Medits }\end{array}$ & $\begin{array}{l}\text { STS } \\
\text { Medits }\end{array}$ & $\begin{array}{l}\text { SOS } \\
\text { Grund }\end{array}$ & $\begin{array}{l}\text { STS } \\
\text { Grund }\end{array}$ & $\begin{array}{c}\Delta \mathrm{t} \\
\text { Grund-Grund }\end{array}$ & $\begin{array}{c}\Delta \mathrm{t} \\
\text { Medits-Medits }\end{array}$ & $\begin{array}{c}\Delta \mathrm{t}-\mathrm{SOS} \\
\text { Medits-Grund }\end{array}$ & $\begin{array}{c}\Delta \mathrm{t}-\mathrm{STS} \\
\text { Medits-Grund }\end{array}$ & $\begin{array}{c}\Delta \mathrm{t} \\
\text { Overall }\end{array}$ \\
\hline 1994 & $11 / 6$ & $27 / 6$ & $7 / 10$ & $4 / 10$ & 3 & -16 & 118 & 99 & 19 \\
\hline 1995 & $3 / 6$ & $22 / 6$ & $10 / 10$ & $5 / 10$ & 5 & -19 & 129 & 105 & 24 \\
\hline 1996 & $31 / 5$ & $17 / 6$ & $11 / 10$ & $17 / 10$ & -6 & -17 & 131 & 120 & 11 \\
\hline 1997 & $3 / 6$ & $16 / 6$ & $8 / 9$ & $25 / 9$ & -17 & -13 & 95 & 94 & 1 \\
\hline \multirow[t]{2}{*}{1998} & $16 / 6$ & $6 / 6$ & $17 / 9$ & $16 / 9$ & 1 & 10 & 91 & 100 & -9 \\
\hline & & & & $\underset{\text { sd }}{\text { Mean }}$ & $\begin{array}{c}-2.8 \\
9.0\end{array}$ & $\begin{array}{c}-11.0 \\
11.9\end{array}$ & $\begin{array}{c}112.8 \\
18.8\end{array}$ & $\begin{array}{c}103.6 \\
10.0\end{array}$ & $\begin{array}{c}9.2 \\
13.4\end{array}$ \\
\hline
\end{tabular}
$\Delta \mathrm{t}$ SOS $-\Delta \mathrm{t}$ STS; sd = standard deviation 

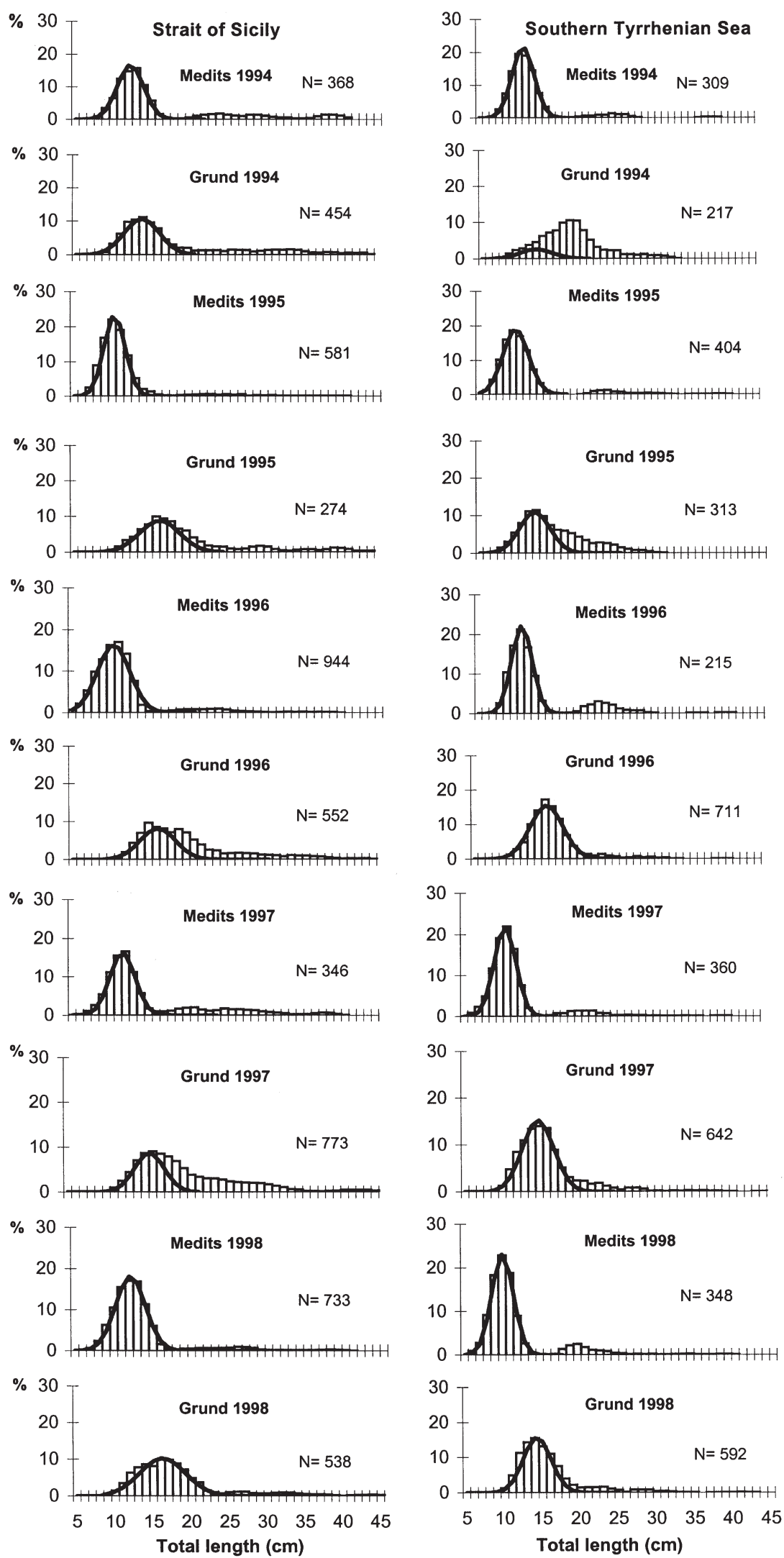

FIG. 2. - Length frequency distributions (total length, in percentage) of Phycis blennoides obtained in MEDITS (spring) and GRUND (autumn) surveys (1994-1998) in the Strait of Sicily (SOS) and the Southern Tyrrhenian Sea (STS). The estimated (NORMSEP) first normal component is superimposed. $\mathrm{N}$ indicates the overall number of specimens. 
trend was detected with the GRUND surveys. Within each subunit, the lag-time between the MEDITS and GRUND surveys were similar, although it was higher for the SOS than the STS. The difference between the overall lag-times of the two subunits appeared quite variable: from a minimum of -9 to a maximum of 24 days $(\Delta \mathrm{T}$ Overall in Table 1$)$.

The length frequency distributions (LFD; \%) per subunit, type of survey and year, with the first estimated components overlapped, are presented in Fig. 2a,b. The MEDITS-LFD showed a higher homogeneity than the corresponding GRUND-LFD, no matter the year or subunit considered. The almost totality of the MEDITS samples was represented by the recruits of 0 group $(8-16 \mathrm{~cm})$. Especially in the SOS, one $(20-35 \mathrm{~cm}$ ) or two (at about $40 \mathrm{~cm}$ ) less numerous groups of fish were detectable in the larger size classes. Looking at the GRUND-LFD, a high variability was immediately perceptible. In some cases, the first component was not well definable (two contiguous modes) and skewed (1994 and 1995 for STS, and 1996 and 1997 for SOS). Given the aim of the paper, the problem was solved by considering the $1^{\text {st }}$ appreciable component for the analysis. Although such a procedure can lead to an underestimation of growth rates, it does not invalidate the overall comparison.

The modal progression of the first group was always evident (Fig. 2a,b). Conversely, the graphical analysis of the other groups was hampered by the predominance of the recruits in the MEDITS surveys and by the piling up of the old cohorts.
The numeric results of the LFD decomposition are presented in Table 2. As expected on the base of the shape (Fig. 2), the estimated mean lengths by year showed a higher homogeneity in the MEDITS than in the GRUND surveys. With the exception of 1996 in both surveys, the mean lengths were significantly different between the two areas. In particular the SOS showed higher mean length than STS in all cases, except the 1995 MEDITS survey. In considering these results, it must be noted that the large size of the samples used makes the t-test more restrictive. Both the absolute $(\Delta \mathrm{l})$ and relative $\left(\Delta \mathrm{l}_{\rho}\right)$ differences (Table 2) differed little between the two kinds of surveys, suggesting a consistency in the analysis, in spite of the problems in separating the $1^{\text {st }}$ GRUND component in some cases. A similar consistency, although of opposite sign, characterized the proportion of the first component (Table 2): the single (mean by year) and overall (great mean) value was higher in the STS than SOS (the overall number of specimens in Table 2 must be considered only as indicative, given the differences in the number of hauls between the surveys). The differences in proportion were only relative and cannot be used as an absolute measure of the recruitment strength. In any case, the variations are not dramatic in MEDITS (great mean of $86 \%$ vs $79 \%$ for STS and SOS, respectively), whereas a great dispersion affected the GRUND data (sd of 0.23 and 0.18 for STS and SOS, respectively).

The plot and fitted curves between the relative difference in length $\left(\Delta \mathrm{l}_{\rho}\right)$ and the time lag for MED-

TABLE 2. - Mean (total) length of the first component, absolute $(\Delta \mathrm{l})$ and relative $(\Delta \mathrm{l} \rho)$ difference, total number of specimens and the proportion of the $1^{\text {st }}$ component (p) for each survey and subunit (Strait of Sicily, SOS and Southern Tyrrhenian Sea, STS); sd = standard deviation.

\begin{tabular}{|c|c|c|c|c|c|c|c|c|c|c|c|}
\hline \multirow{2}{*}{$\begin{array}{l}\text { Survey } \\
\text { year }\end{array}$} & \multicolumn{2}{|c|}{ SOS length } & \multicolumn{2}{|c|}{ STS length } & \multirow[b]{2}{*}{$\mathrm{p}$ of t-test } & \multirow[b]{2}{*}{$\Delta \mathrm{l}$} & \multirow[b]{2}{*}{$\Delta \mathrm{l} \rho$} & \multicolumn{2}{|c|}{ SOS } & \multicolumn{2}{|c|}{ STS } \\
\hline & Mean & $\mathrm{sd}$ & Mean & $\mathrm{sd}$ & & & & $\begin{array}{l}\text { Total number } \\
\text { specimens }\end{array}$ & $\begin{array}{l}\mathrm{p} \text { of first } \\
\text { component }\end{array}$ & $\begin{array}{l}\text { Total number } \\
\text { specimens }\end{array}$ & $\begin{array}{l}\mathrm{p} \text { of first } \\
\text { component }\end{array}$ \\
\hline \multicolumn{12}{|l|}{ MEDITS } \\
\hline 1994 & 12.3 & 1.84 & 11.4 & 1.66 & $<0,0000$ & 0.900 & 1.30 & 368 & 0.73 & 309 & 0.87 \\
\hline 1995 & 10.0 & 1.44 & 10.3 & 1.88 & 0.0051 & -0.330 & -0.476 & 581 & 0.76 & 404 & 0.92 \\
\hline 1996 & 11.2 & 1.94 & 11.0 & 1.46 & 0.9900 & 0.200 & 0.288 & 944 & 0.87 & 215 & 0.81 \\
\hline 1997 & 11.4 & 1.77 & 10.6 & 1.63 & $<0,0000$ & 0.800 & 1.153 & 346 & 0.71 & 360 & 0.88 \\
\hline 1998 & 11.9 & 1.91 & 10.0 & 1.46 & $<0,0000$ & 1.900 & 2.738 & 733 & 0.90 & 348 & 0.85 \\
\hline Great mean & 11.4 & & 10.7 & & & 0.69 & & & 0.79 & & 0.86 \\
\hline sd & 0.9 & & 0.6 & & & 0.84 & & & 0.08 & & 0.04 \\
\hline \multicolumn{12}{|l|}{ GRUND } \\
\hline 1994 & 14.2 & 1.92 & 13.3 & 2.64 & 0.0010 & 0.90 & 0.65 & 454 & 0.54 & 217 & 0.31 \\
\hline 1995 & 16.2 & 2.75 & 12.6 & 2.26 & $<0,0000$ & 3.60 & 2.61 & 274 & 0.59 & 313 & 0.64 \\
\hline 1996 & 15.4 & 2.02 & 15.2 & 2.21 & 0.1041 & 0.20 & 0.145 & 552 & 0.47 & 711 & 0.90 \\
\hline 1997 & 14.8 & 1.86 & 14.5 & 2.14 & 0.0310 & 0.30 & 0.218 & 773 & 0.31 & 642 & 0.79 \\
\hline 1998 & 16.0 & 3.11 & 14.1 & 1.94 & $<0,0000$ & 1.89 & 1.372 & 538 & 0.81 & 592 & 0.80 \\
\hline Great mean & 15.3 & & 13.9 & & & 1.38 & & & 0.54 & & 0.69 \\
\hline $\mathrm{sd}$ & 0.8 & & 1.0 & & & 1.41 & & & 0.18 & & 0.23 \\
\hline
\end{tabular}




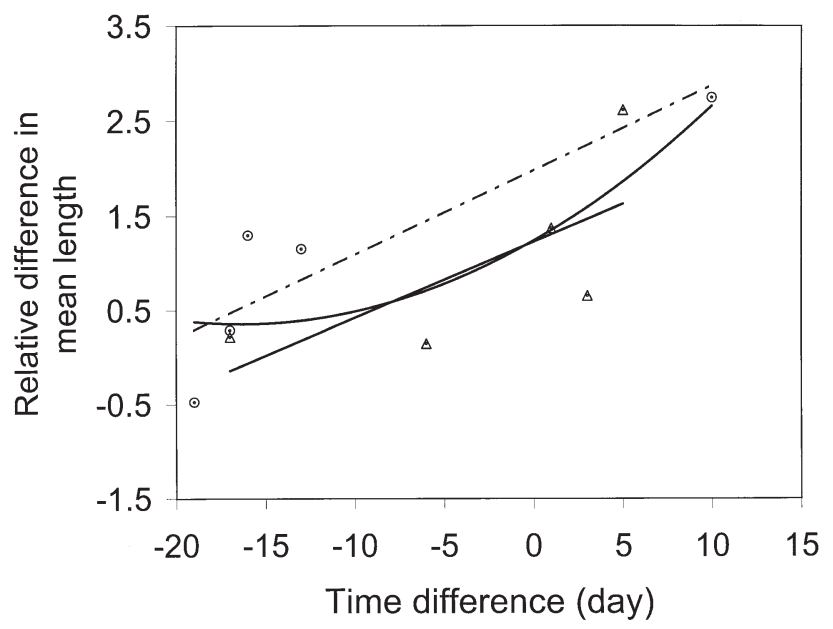

FIG. 3. - Relative difference in mean lengths versus time difference in day (GRUND-GRUND and MEDITS-MEDITS) of the first normal component in the sizes of Phycis blennoides. Circles and triangles denote MEDITS and GRUND surveys. The fitted straight line refers to MEDITS (dotted; $r=0.88$ ) and GRUND (solid; $r=0.70)$ data; the parabolic relationship $(r=0.77)$ refers to the combined data.

ITS and GRUND surveys are presented in Figure 3. A straight line fitted quite satisfactorily the data of the MEDITS surveys $(\mathrm{r}=0.88 ; \mathrm{p}=0.048)$, while the regression was not significant in the GRUND case $(r=0.70 ; p=0.186)$. A curvilinear relationship seems a plausible alternative for the pooled data. In spite of the poor fitting, given the limited number of surveys, the hypothesis that the LFD mean estimates were affected by the time delay effect is strongly supported. In particular, since the earlier the SOS begins its surveys the smaller becomes the difference in length, these results might support the hypothesis of a precocious recruitment of Phycis blennoides in the Southern Tyrrhenian Sea or a difference in the growth rates between the two populations.

The instantaneous growth values, standardized to 1 month (Table 3), resulted slightly higher for the STS recruits than the corresponding values of the SOS in all years except 1995. Even including this anomalous value (Fig. 4), the differential is not sig-

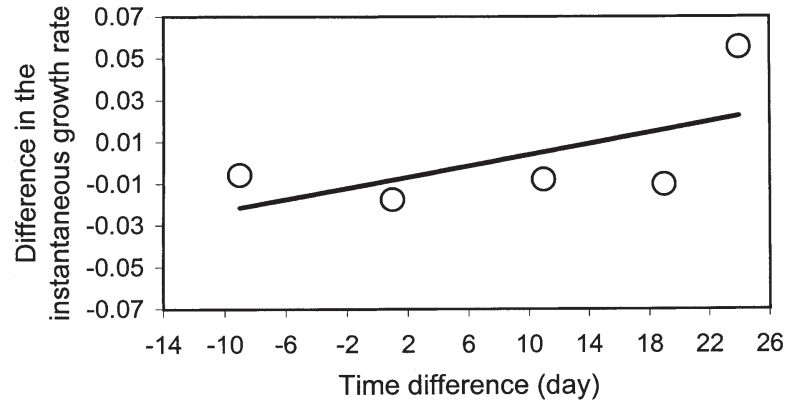

FIG. 4. - Difference in instantaneous monthly growth rate $(\mathrm{G})$ versus overall time difference in day of the first component of Phycis blennoides with the fitted line $(\mathrm{r}=0.61)$.

nificantly correlated to the overall time lag $(r=0.60$; $\mathrm{p}=0.286$ ). Furthermore, both absolute and instantaneous growth rates do not differ statistically between the two areas (Table 3). Only excluding the 1995 point, the difference in growth rates indicates that the recruits of Phycis blennoides of STS grew slightly faster (about 1\%) than their counterparts of the SOS. This result, however, is opposite to what might have been expected from data in Table 2, therefore further supporting the hypothesis of an earlier recruitment of Phycis blennoides in the Southern Tyrrhenian Sea. Consequently, there is strong evidence that the higher mean lengths observed in SOS samples mainly reflect the lag-time in the surveys conducted by the SOS, whereas the growth rates between the two subunits are practically indistinguishable.

\section{DISCUSSION}

Although limited to the length structure, the above results suggest that MEDITS and GRUND data gathered in the two investigated areas can be integrated. The spring cohort is always well defined and the symmetry of the mode supports the nonselective property of the cod-end used in the MED-

TABLE 3. - Absolute (g) and instantaneous (G) growth rates, expressed per month, by subunit and year. The differences in $\mathrm{G}(\Delta \mathrm{G})$ between the Strait of Sicily (SOS) and the Southern Tyrrhenian Sea (STS) are also reported.

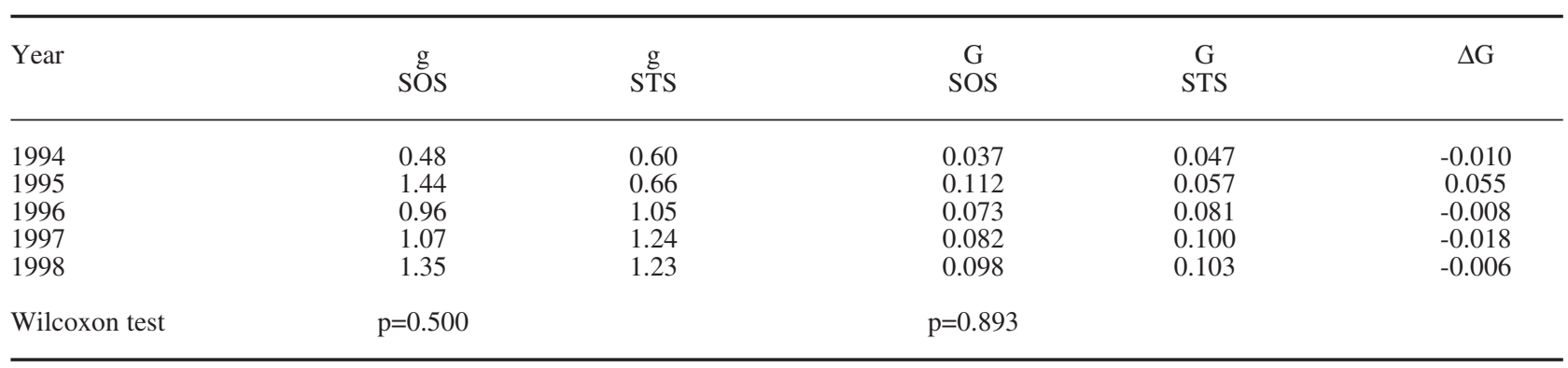


ITS gear (20 mm mesh stretched). The cod-end employed in the GRUND gears is generally slightly larger (30 and $36 \mathrm{~mm}$ for SOS and STS, respectively), but selectivity trials with a GRUND gear mounting a cod-end with $40 \mathrm{~mm}$ mesh stretched resulted in a full retention of Phycis blennoides in autumn $\left(\mathrm{TL}_{50 \%}=8.1 \mathrm{~cm}\right.$, D’Onghia et al., 1998).

The assessment of the modal progression of the spring component was allowed by the GRUND data, which also showed a well-defined component in 4 over 6 years. A second minor recruitment pulse, the difference in growth between male and female young-of-the-year, or differential overlapping with the specimens recruited in the previous year (evidenced as the small component in the MEDITS data at about 20-25 cm; Fig. 2a, b) might explain the anomalies of the GRUND surveys 1996-1997 (SOS) and 1994-1995 (STS).

Furthermore, both MEDITS and GRUND data are coherent with the general biological knowledge of the Mediterranean populations of Phycis blennoides which are characterized by a discrete recruitment in spring (Bilio, 1969; D'Onghia et al., 1989; Biagi and Farnocchia, 1994; Massutí et al., 1996). This recruitment period is consistent with data on reproduction. In fact, although the identification of the spawning period is still uncertain, given the low number of sexually mature females found (Belcari and Biagi, 1999), mature specimens were found in summer in the Catalan Sea (Gallardo-Cabello and Gual-Frau, 1984) and December (Massutí et al., 1996). The development of male gonado-somatic indices in the Ligurian Sea suggests that spawning occurs from July to October with maximum intensity attained in August and September (Fanciulli and Relini Orsi, 1979). On the basis of two mature females, gathered during November and January, Tursi et al. (1995) proposed that reproduction in the Ionian Sea occurs in autumn and early winter.

A size-specific distribution with depth, a sex-specific growth (male growth falls at $18-21 \mathrm{~cm}$ of TL) and a progressive reduction in availability to the bottom trawl with increasing size, given that adults occur mainly nearby hard bottoms and caves, has been reported (Campillo, 1992; FishBase, 1998; Belcari and Biagi, 1999).

Concerning the length structure of the Mediterranean populations (Campillo, 1992; Belcari and Biagi, 1999), the spring recruits are clearly distinguished from the components of the parental stock. A similar pattern, although with different modal length, characterizes also the Atlantic populations (Casas and Pineiro, 2000)

Recruit growth rates obtained in different areas of the Mediterranean from modal progression analysis, show a high consistency. Young recruits collected by Bilio (1969) in the Eastern Ligurian Sea grew from $8.5 \mathrm{~cm}$ in April 1967 to $19.2 \mathrm{~cm}$ TL in December 1968, showing a mean growth rate of $1.07 \mathrm{~cm}$ per month. A very similar rate $(1.12 \mathrm{~cm}$ per month) was found in the cohort recruited in April 1977 with $6 \mathrm{~cm}$ of modal standard length (SL), which showed a mode of $15 \mathrm{~cm}$ SL in December 1977 (Fanciulli and Relini Orsi,1980). An average rate of $1.2 \mathrm{~cm}$ per month was computed with data presented in D'Onghia et al. (1998) for the Ionian Sea, who reported, for the cohorts recruited in spring 1985, 1986 and 1987, a mode of $9 \mathrm{~cm}$ in April/May and 15 $\mathrm{cm}$ TL in September/October. In the North Tyrrhenian Sea, Biagi and Farnocchia (1994) found a mean growth rate of about $1 \mathrm{~cm}$ per month in the cohorts recruited in April 1991 and April 1992. Massutí et al. (1996), off the Catalan coast, found a mean rate of $0.99 \mathrm{~cm}$ per month in the cohort recruited in April 1991, with a mean of $7.3 \mathrm{~cm} \mathrm{TL}$, and reaching a mean of $15.2 \mathrm{~cm}$ TL in December 1991. All these data are consistent with the mean growth rate found in the present work $(1.03$ and $0.93 \mathrm{~cm}$ per month in SOS and STS, respectively).

In spring, the recruits represent up to $90 \%$ of the whole trawl catch, the smallest length class (4.5-5.0 $\mathrm{cm})$ observed are close to the size of transition from the pelagic life to the demersal one, i.e. $3.0-4.6 \mathrm{~cm}$ (D'Ancona, 1933).

Given the difference in recruit proportions, the following hypothesis may be of interest: such slight variations in growth rates between the two subunits might reflect the incidence of density-dependence phenomena, both intra- or inter- cohorts.

Although coherent with general knowledge about the populations, actual data would have suggested, at a first insight, that some systematic differences in mean size and growth rate concern the two investigated subareas. This impression is strongly modified after having included the lag-time by the exploratory procedure, in spite of its relative simplicity. The results of the procedure indicate that there is only a slight difference in growth rate and that the observed differences in mean length likely derive from a delay in recruitment, probably linked to the latitudinal variations or geographical environment/population characterizations (currents, temperature, light shift in the unknown spawning peak, etc.). 
It must remembered that the proposed procedure is not aimed at assessing the dynamics of the investigated stocks of Phycis blennoides (for example, the LFD must be analysed by sex), but it remains valid to point out the incidence of lag-time, which can be quite high when distant subareas are considered.

In conclusion, the results of the proposed three steps procedure can be synthesized as follows: (a) no effect in step 2 and 3: therefore, differences in recruitment and growth, if any, are not identifiable and the two sets of data can be reasonably combined without any treatment; (b) effect in both step 2 and 3: therefore, differences in populations dynamics both as shifted recruitment and lower/higher growth rate are likely to occur; (c) effect in step 2, but not in step 3: therefore, there is a shift in recruitment, but not in growth rate; (d) no effect in step 2 but only in step 3: therefore, recruitment periodicity is the same but the two populations show an initial different growth rate.

In any case, present results clearly indicate the advantage in using both MEDITS and GRUND data sets in assessing the demersal resources and the opportunity to maintain the present sampling frame in the future.

\section{REFERENCES}

Belcari, P. and F. Biagi. - 1999. Phycis blennoides. In: G. Relini, J. Bertrand and A. Zamboni (eds.), Synthesis of Knowledge on Bottom Fishery Resources in Central Mediterranean (Italy and Corsica). Biol. Mar. Medit., 6 (suppl.1): 189-196.

Bertrand, J.A., L. Gil de Sola, C. Papaconstantinou, G. Relini and A. Souplet. -2000 . An international bottom trawl survey in the Mediterranean: the MEDITS programme. In: J.A. Bertrand and G. Relini (eds.), Demersal resources in the Mediterranean, Proceedings of the Symposium held in Pisa, 18-21 March 1998, Actes de Colloques 26, pp. 76-93. IFREMER, Plouzané.

Biagi, F. and I. Farnocchia. - 1994. Reclutamento ed accrescimento di Phycis blennoides Brunnich, 1768 nel Mar Tirreno settentrionale. Biol. Mar. Medit., 1(1): 295-296.

Bilio, M. - 1969. La variabilità tra pescate effettuate con rete a strascico nel Mar Ligure. Pubbl. Staz. Zool. Napoli, 37 suppl.: $115-131$.

Campillo, A. - 1992. Les pêcheries françaises de Méditerranée: Synthèse des connaissances. RIDRV-92/019-RH Sète. 206 p.

Casas J.M. and C. Pineiro. - 2000. Growth and age estimation of Greater Fork-beard (Phycis blennoides Brunnich, 1768) in the North and North-West of the Iberian Peninsula (ICES Division VIIIc and IX a). Fish. Res., 47: 19-25.

D’Ancona, U. - 1933. Uova, larve e stadi giovanili di Teleostei.
Fauna e Flora del Golfo di Napoli, 38: 232238

D’Onghia, G., F. Mastrototaro, P. Maiorana and M. Basanisi. 1998. Selettività della rete a strascico utilizzata sui fondi di scarpata (250-750 m) dello Ionio (Mediterraneo Centrale). Biol. Mar. Medit., 5(2): 437-448.

D’Onghia, G., A. Tursi, A. Matarrese, R. Pollicoro and C. Caroppo. - 1989. Alcuni aspetti biologici e gestionali della pesca di Merluccius merluccius, Micromesistius poutassou, Phycis blennoides e Mullus barbatus nel Mar Jonio. Nova Thalassa, 105(Suppl.1): 417-424.

Fanciulli G. and L. Relini Orsi.- 1979. Biologia di Phycis blennoides (Brunn.). 2. Rapporto sessi e osservazioni sulla maturità sessuale. Atti Soc. Tosc. Sci. Nat., Mem., ser.B, 86, suppl.: 384-387.

Fanciulli G. and L. Relini Orsi. - 1980. Biologia di Phycis blennoides (Brunn.). 3. L'accrescimento. Mem. Biol. Mar. Oceanogr., Suppl. 10: 391-392.

Fiorentini, L., P.Y. Dremière, I. Leonori, A. Sala and V. Palumbo. - 1998. Ulteriori osservazioni sulle prestazioni delle attrezzature a strascico impiegate per la valutazione delle risorse demersali in Italia. Biol. Mar. Medit., 5(3): 156-165.

Fiorentini, L., G. Cosimi, A. Sala, I. Leonori and V. Palumbo-1999. Efficiency of the bottom trawl used for Mediterranean international trawl survey (MEDITS). Aquat. Living Resour., 12(3): 187-205

FishBase. - 1998. FishBase 98 CD-ROM. ICLARM, Manila.

Gallardo-Cabello, M. and A. Gual-Frau. - 1984. Consideraciones bioecológicas durante el crecimiento de Phycis blennoides (Brunnich, 1768) en el Mediterráneo occidental (Pisces:Gadidae). An. Inst. Cienc. Mar Limnol. Univ. Nal. Auton. México, 11(1): $225-238$

Gayanilo, F.C.Jr., P. Sparre and D. Pauly. - 1996. The FAO-ICLARM Stock Assessment Tools (FiSAT) User's Guide. FAO Computerized Information Series (Fisheries) No.8 Rome, FAO.126 p.

Greco, S., P. Rinelli, D. Giordano and F. Perdichizzi. - 1998. Valutazione delle risorse demersali da Capo Suvero a San Vito lo Capo (Tirreno meridionale). Biol. Mar. Medit., 5(3): 74-84.

Hilborn, R. and C.J. Walters.- 1992. Quantitative Fisheries Stock Assessment. Choice, Dynamics and Uncertainty. Chapman and Hall, London.

Levi, D., S. Ragonese, M.G. Andreoli, G. Norrito, P. Rizzo, G.B. Giusto, S. Gancitano, G. Sinacori, G. Bono, G. Garofalo and L. Cannizzaro. - 1998. Sintesi delle ricerche sulle risorse demersali dello Stretto di Sicilia (Mediterraneo Centrale) negli anni 1985-1997 svolte nell'ambito della legge 41/82. Biol. Mar. Medit., 5(3): 130-139.

Massutí, E., B. Morales-Nin and D. Lloris. - 1996. Bathymetric distribution and recruitment patterns of Phycis blennoides (Pisces:Gadidae) from the slope of the northwestern Mediterranean. Sci. Mar,. 60(4): 481-488.

Pennington, M. and T. Stromme. -1998 . Surveys as a research tool for managing dynamics stocks. Fish. Res., 37: 97-106.

Relini, G. - 2000. Demersal trawl surveys in Italian Seas: a short review. In: J.A. Bertrand and G. Relini (eds.), Demersal resources in the Mediterranean, Proceedings of the Symposium held in Pisa, 18-21 March 1998, Actes de Colloques 26, pp. 7693. IFREMER, Plouzané.

Ricker, W.E. - 1979. Growth rates and Models. In: W.S. Hoar, D.J. Randall and J.R. Brett (eds.), Fish Phisiology. Volume VIII. Bioenergetics and growth, pp. 678-743. Academic Press, New York.

SYSTAT. - 1998. Systat for Windows. Statistics Version 8.0. Systat, Inc., Evanston, IL.

Tursi, A., M. Panza, M. Basanisi, G. Costantino and G. D'Onghia. - 1995. Rinvenimento di esemplari con gonadi mature di Phycis blennoides (Pisces, Osteichthyes) nel batiale del Mar Ionio. Biol. Mar. Medit., 2(2): 295-297. 